\title{
Socially Sustainable Manufacturing: Exploring the European Landscape
}

\author{
Paola Fantini ${ }^{1}$, Claudio Palasciano ${ }^{2,}$ Marco Taisch ${ }^{2}$, \\ Cecilia Berlin ${ }^{3}$, Caroline Adams ${ }^{3}$, and Johan Stahre ${ }^{3}$ \\ ${ }^{1}$ Fondazione Politecnico di Milano \\ ${ }^{2}$ Politecnico di Milano, Department of Management, \\ Economics and Industrial Engineering, Milan, Italy \\ ${ }^{3}$ Chalmers University, Goteborg, Sweden \\ paola.fantini@fondazione.polimi.it, \\ \{marco.taisch, claudio.palasciano\} @polimi.it, \\ \{cecilia.berlin, cadams, johan.stahre\} @chalmers.se
}

\begin{abstract}
Sustainable manufacturing has been extensively researched in the last decades, however there is a lack of coherence in literature specifically addressing its social dimension. Within the framework of the Social Sustainabilitythemed project SO SMART (Socially Sustainable Manufacturing for the Factories of the Future), a preliminary explorative survey and interview study were deployed among manufacturing companies and their stakeholders in Europe to investigate the extent to which they understand and practice social sustainability in relation to their business activities and context. Using an inquiry approach based on the main concepts related to social sustainability found in literature, this paper reports findings on preliminary exploration of the European landscape of social sustainability-related practices from a corporate and societal perspective. Findings contribute to the creation of a basis of shared knowledge as a prerequisite for extending and further developing concepts and models for socially sustainable manufacturing ecosystems.
\end{abstract}

Keywords: social sustainability, sustainable manufacturing ecosystems.

\section{$1 \quad$ Introduction}

Within the framework of the SO SMART (Socially Sustainable Manufacturing for the Factories of the Future) project, this paper reports on a study for exploring the European landscape of social sustainability-related practices and concerns, both from a corporate and societal perspective. The central concept of SO SMART is in fact to investigate social sustainability from a "balanced Eco-system" perspective, taking into account the viewpoints of the individual, industry and society [1].

Sustainability is an anthropocentric value that essentially pursues inter-and intragenerational justice [1]. Modern discourse regarding sustainability propagates a triad view, first discussed at the 1992 Rio de Janeiro earth summit [2] and addressing the three "pillars" of economic, environmental and social sustainability as equal and 
parallel concerns; however, they have so far not been given the same focus. Particularly the social dimension has not been sufficiently explored [1] [3] and the European Factory of the Future Research Association has indicated that social sustainability in manufacturing is among the main challenges and opportunities of the recently issued 2014-2020 Roadmap. The roadmap promotes research to increase human achievements in future European manufacturing to create sustainable, safe and attractive workplaces for Europe 2020, and to achieve sustainable care and responsibility for employees and citizens in global supply chains [4].

Literature specially referring to social sustainability for manufacturing is rather limited and dispersed over different scopes: the global, super-national and national level for industry, public authorities and academia [5], the engineering field [6], science, engineering and manufacturing and the challenges ahead [7], [8], [9], [10].

The scope of social sustainability for manufacturing still appears insufficiently explored and, considering the substantial socio-economic impact of this sector, further investigations and developments are potentially promising.

\section{Research Approach}

The approach followed to obtain a preliminary view of the socially sustainable European manufacturing landscape encompasses: a literature study, which is not reported in this paper directly but through the references in the following steps; an analysis framework; an explorative study, including interviews to stakeholders and a survey to manufacturing companies.

\subsection{Analysis Framework}

The set of relevant topics identified during the literature study paved the way for the development of an analysis framework, addressing three main facets: A. Profile of social sustainability, reflecting how sustainability is understood and enacted/interpreted, on the basis of sustainability reporting standard practices (i.e. [11]) and of some innovative concepts related to cultural factors derived from the literature analysis; B. Practices for social sustainability, describing the specific actions and practices in place, mostly based on well-established sustainability frameworks; $\mathbf{C}$. Maturity and measurement of social sustainability, defining the implementation level, grounded on well-established reporting standards and further tailored to the purpose of the survey, taking into account the sustainability profile and additional concepts derived from the literature study.

The following paragraphs report, for each facet, some of the most significant topics identified to be addressed in the survey, along with the references from the literature research that were used to shape the questionnaires.

\section{A. Profile of social sustainability}

- Dimensions and relevance of sustainability. The survey addressed the relevance attributed to economic, environmental and social sustainability. Among the main references [12], [13](triple bottom line) and [14] (related issues). 
- Scope of social sustainability. The survey queried whether broad areas (social themes, labour policies, social equity in the supply chain, community involvement and CSR) are considered in the scope of social sustainability for manufacturing. The topics were adapted from impact categories, i.e. [15] and social sustainability terms and definitions [16], [17].

- Drivers and barriers. The survey investigated the relevance attributed to a list of drivers and barriers that affect social sustainability intentions and performances. References were found in [18] (variety of barriers and enablers), [19] (driving forces towards CSR), [20] (internal and external pressure).

- Orientation towards the stakeholders. The survey aimed at identifying the prevailing attitudes towards stakeholders, distinguishing if the target is the benefit of the company, of the stakeholders or of a wider community, based on [21], [22], [23].

- Philosophy of social responsiveness. The survey researched the prevailing type of commitment towards social requirements along a reactivity - proactivity scale [13]. The extreme of the scale has been tentatively extended to include the representation of the Creating Shared Value perspective [24].

\section{B. Practices for social sustainability}

- Social sustainability Practices. The survey queries about the social sustainability practices deployed. Labor practices: human capital development, work-life balance, learning, talent management, employees' turnover and satisfaction management, temporary work, etc. Stakeholders and communities practices: supply chain code of conduct, customer relationship management, risk and crises management, etc.. See [20], [25], [26], [27], [28], [29], [30].

\section{Maturity and measurement of social sustainability}

- Social Sustainability vision and values. The survey aims at determining the degree of clarity, understanding and acceptance of the social sustainability vision within the company, based on [12], [13] (relevance of setting and communicating the vision) and [31] (issues related to disseminating the vision within the organization).

- Implementation of social sustainability in the systems and processes. The questions aim at assessing to what extent social sustainability is integrated into practices and affects activities [32].

- Relationship with the stakeholders. The topic concerns the involvement of different categories of stakeholders in the process of defining, implementing and evaluating sustainable performance. References come for [1], [31], [5] (competitors, suppliers, investors and NGOs) and [6] (current/ prospective workers, local community).

- Social sustainability periodical reporting. Inquiries about the reporting methods, actors and procedures. The questions have taken into account [33] (readers' expectations and following actions and [14] (stakeholders involvement).

\subsection{Explorative Study}

The study, including a survey and stakeholders' interviews, was intentionally stated to be a pilot effort targeted at the following objectives: a) to verify whether the topics and themes identified by reviewing the scientific literature are adequate to represent 
social sustainability orientations and practices in manufacturing; and if not, to explore missing concepts or perspectives; b) to obtain a preliminary picture of how social sustainability is currently conceived and implemented in European manufacturing.

The survey consisted of multiple-choice questions structured on the analysis framework described in 2.1, complemented with open questions. The survey was deployed online, targeting a sample of European industrial actors and stakeholders. The first pilot phase reached 9 countries and 8 industrial sectors, eliciting a pilot sample of 21 responses, including small and large enterprises, both national and multinational, with different situations and trends in terms of profitability and employment development.

To gain a multi-level eco-systemic perspective, the interviews were conducted mainly with stakeholders from various societal functions concerned with social sustainability. The interviews were semi-structured and aimed to identify any areas and practices of social collaboration between company and societal stakeholders, again with questions based on the analysis framework. Through the SO SMART project partners' networks, 8 individuals representing local or regional authorities, trade unions and enterprises were interviewed as relevant stakeholders affected by company practices of social sustainability. Interviewed stakeholders represented Public Authorities at NUTS $^{1}$ levels 2 and 3, Local Authorities, Industrial Associations and Trade Unions.

\section{Preliminary Landscape}

Taking into account the previously stated pilot nature of the respondent sample, the survey and the interviews to manufacturing companies shows wide recognition among the respondents of the relevance of the triad of economic, environmental and social dimensions of sustainability; however, the importance of the latter is slightly less perceived. Moreover, the broad social themes are considered partially or not in the scope of social sustainability for manufacturing, ranking below labor policies, community involvement and social equity in the supply chain.

The survey responses also suggested that the most important drivers influencing a company's level of action are: positive pressure exerted both by internal stakeholders (i.e. top management and employees) and external stakeholders (customers and local authorities $)^{2}$ and the explicit alignment of social sustainability with the company's strategy. Moreover, the survey, complemented by the interview results, highlighted that some important barriers to social sustainability still need to be addressed in order to progress towards a more extended and fully deployed social sustainability, namely: the difficulty in evaluating the benefits coming from social sustainability practices, in particular the difficulty of translating them into easily measurable and quantifiable terms; the existence of unsupportive cultures, both at the organizational and societal level, that promote values and behaviors not aligned to social sustainability principles; the lack of strong collaborative relationships with stakeholders in order to develop shared visions and strategies to achieve common goals.

\footnotetext{
${ }^{1}$ Nomenclature of Territorial Units for Statistics http://ec.europa.eu/eurostat/ramon/index.cfm?TargetUrl=DSP_PUB_WELC

${ }^{2}$ For the majority of the enterprises, employees and customers, followed by public authorities and trade unions, are the main stakeholders that enterprises interact with.
} 
Although in the presence of some ambiguities, findings seem to outline a population of manufacturers on the whole who are aware of the relevance of social sustainability; who in most of the cases have developed their vision and culture; who have identified, adopted and implemented practices; and who have set up reporting. However, some heterogeneities and discrepancies require further elaboration. The respondents seem to have different levels of understanding and adhesion with reference to social sustainability, which we may exemplify through two "polar" types. The type of "cold/recent adopters", who seem to start from mere acknowledgement of the relevance of social sustainability with a prevalent inward focus, leading to the definition of a vision that remains fuzzy, not accepted/internalized at all levels of the organization nor incorporated in a planning and control process. This type implements specific practices mostly addressing employees and has them integrated in existing processes, in some cases issuing reports about the activities carried out and the resources employed.

A different type is that of the "warm/mature adopters", who embrace social sustainability, consider a wider scope including external stakeholders whom they approach for collaboration, have clearly defined visions and strategies and have deployed them, or are in the process of deploying them, through an integrated framework and a closed-loop planning and control cycle, using performance indicators, involving external stakeholders and/or leveraging external data sources.

We can draw here some preliminary directions for further research, which most likely has to shed more light on the potential multiplicity of socially sustainable manufacturing types, here preliminarily condensed in the two "polar" types evidenced above. Furthermore it seems some investigation should be performed in more detail on i) the role of the temporal/maturity dimension, in order to better distinguish the degree of interest towards social sustainability from the duration of experience, and ii) the assessment and reporting methodologies enacted and the performance indicators monitored by companies.

\section{Discussion}

The work presented in this paper constitutes a pilot step supporting a wider research and road-mapping effort aimed at developing new models for sustainable manufacturing ecosystems pursuing social, environmental and economic performance objectives.

In the survey, difficulties occurred in interpreting some results: this may indicate that some sub-categories need to be more clearly defined. In terms of deployment, the survey reached a limited number of actors, so it is not sufficient to represent the manufacturing sector as a whole, but it is still valuable as a preliminary exploration. Further issues to address in continued efforts include better coverage of the variety of stakeholders and industry sectors.

Some deficiencies are intrinsic of the survey format, which helped us to highlight current practices, but could not support the elicitation of needs. The individual interviews, aiming at complementing the survey with the desired richness, provided additional elements useful for interpreting the results and for pointing out preliminary directions for further exploratory activities. 
In the prosecution of the research, in order to encourage the emergence and development of novel visions, approaches that better leverage the interaction among groups of people and stimulate new ideas (such as Delphi, focus groups or workshops) will be exploited.

\section{Conclusions}

In spite of the pilot nature of the study deployment, the research has enabled drawing of a preliminary picture of socially sustainable manufacturing, as currently understood and implemented in Europe. The findings are useful to point out relevant directions and topics for later exploration in collaborative workshop formats and similar. The preliminary results from the survey and interviews appear to confirm the substantial comprehensiveness of the framework obtained from literature.

The findings also contribute to the creation of a basis of shared knowledge as a prerequisite for developing a collective vision for socially sustainable manufacturing ecosystems, requiring the involvement and coordination of multiple organizations. Further work is planned within the SO SMART project to address these challenges.

Acknowledgements. This paper has been developed within the EC funded project SO SMART (GA.608734).

\section{References}

1. Omann, I., Spangenberg, J.H.: Assessing Social Sustainability - The Social Dimension of Sustainability in a Socio-Economic Scenario. In: 7th Biennal Conference of the International Society for Ecological Economics, Soussa, Tunisia (2002)

2. United Nations, Report of The United Nations Conference on Environment and Development, Rio de Janeiro (1992)

3. Colantonio, A.: Social Sustainability: a review and critique of traditional versus emerging themes and assessment methods. In: Sue-Mont Conference 2009: Second International Conference on Whole Life Urban Sustainability and its Assessment, Loughborough, Loughborough University, pp. 865-885 (2009)

4. EFFRA - European Factory of the Future Research Association, Factories of The Future Multiannual Roadmap for The Contractual PPP Under Horizon 2020, Publications Office of the European Union, Luxembourg (2013)

5. Jovane, F., Yoshikawa, H., Alting, L., Boer, C.R., Westkamper, E., Williams, D., Tseng, M., Seliger, G., Paci, A.M.: The incoming global technological and industrial revolution towards competitive sustainable manufacturing. CIRP Annals - Manufacturing Technology (2008)

6. Garetti, M., Taisch, M.: Sustainable manufacturing: trends and research challenges. Production Planning \& Control: The Management of Operations, 83-104 (2012)

7. Haapala, K.R., Zhao, F., Camelio, J., Sutherland, J.W., Skerios, S.J., Dornfeld, D.A., Jawahir, I.S., Clarens, A.F., Rickli, J.L.: A Review of Engineering Research in Sustainable Manufacturing. Journal of manufacturing Science and Engineering 135(4) (2013) 
8. Lanz, M., Majuri, M., Tuokko, R.: Information flows in future advanced manufacturing ecosystems. In: Prabhu, V., Taisch, M., Kiritsis, D. (eds.) APMS 2013, Part I. IFIP AICT, vol. 414, pp. 70-77. Springer, Heidelberg (2013)

9. Berlin, C., Dedering, C., Jónsdóttir, G.R., Stahre, J.: Social sustainability challenges for european manufacturing industry: Attract, recruit and sustain. In: Prabhu, V., Taisch, M., Kiritsis, D. (eds.) APMS 2013, Part I. IFIP AICT, vol. 414, pp. 78-85. Springer, Heidelberg (2013)

10. Fantini, P., Taisch, M., Palasciano, C.: Social sustainability: Perspectives on the role of manufacturing. In: Prabhu, V., Taisch, M., Kiritsis, D. (eds.) APMS 2013, Part I. IFIP AICT, vol. 414, pp. 62-69. Springer, Heidelberg (2013)

11. Global Reporting Initiative, G4, Reporting Principles and Standard Disclosures, Amsterdam (2013)

12. United Nations General Assembly, 2005 World Summit Outcome, United Nations (2005)

13. Elkington, J.: Partnership from cannibals with forks: The triple bottom line of 21 st century business. Environmental Quality Management 8(1), 37-51 (1998)

14. Hubbard, G.: Measuring Organizational Performance: beyond the Triple Bottom Line. Business Strategy and the Environment 18(3), 177-191 (2006)

15. Joung, C.B., Carrell, J., Sarkar, P., Feng, S.C.: Categorization of indicators for sustainable manufacturing. Ecological Indicators 24, 148-157 (2012)

16. McKenzie, S.: Social Sustainability: towards some definitions. Hawke Research Institute Working Paper Series 27 (2004)

17. Vallance, S., Perkins, H., Dixon, J.: What is social sustainability? A clarification of concepts. Geoforum 42(3), 342-348 (2011)

18. Walker, H., Jones, N.: Sustainable supply chain management across the UK private sector. Supply Chain Management: An International Journal 17(1), 15-28 (2012)

19. Reinmann, F., Ehrgott, M., Kaufmann, L., Carter, C.R.: Local stakeholders and local legitimacy: MNEs' social strategies in emerging economies. Journal of International Management 18, 1-17 (2012)

20. Collins, E., Roper, J., Lawrence, S.: Sustainability Practices: Trends in New Zealand. Business Strategy and the Environment 19, 479-494 (2010)

21. Bingham, J.B., Dyer Jr., W.G., Smith, I., Adams, G.L.: A Stakeholder Identity Orientation Approach to Corporate Social Performance in Family Firms. Journal of Business Ethics 99(4), 565-585 (2011)

22. Searcy, C.: Corporate Sustainability Performance Measurement Systems: A Review and Research Agenda. Journal of Business Ethics 107(3), 239-253 (2012)

23. Perrini, F., Russo, A., Tencati, A., Vurro, C.: Deconstructing the Relationship Between Corporate Social and Financial Performance. Journal of Business Ethics 102(1), 59-76 (2011)

24. Carrol, A.B.: Corporate Social Responsibility Evolution of a Definitional Construct. Business and Society 38(3), 268-293 (1999)

25. Theyel, G., Hofmann, K.: Stakeholders relations and sustainability practices of US small and medium-sized manufacturers. Management Research Review 35(12), 1110-1133 (2012)

26. S\&P Dow Jones Indices and RobecoSAM, Dow Jones Sustainability World Index Guide v.12.2, RobecoSAM AG, Zurich (2013)

27. International Organization for Standardization (ISO), Discovering ISO 26000, Geneve (2010)

28. Morali, O., Searcy, C.: A Review of Sustainable Supply Chain Management Practices in Canada. Journal of Business Ethics 117(3), 635-658 (2012) 
29. Ameer, R., Othman, R.: Sustainability Practices and Corporate Financial Performance: A Study Based on the Top Global Corporations. Journal of Business Ethics 108(1), 61-79 (2011)

30. SAM Reasearch AG, SAM Research Corporate Sustainability Assessment Questionnaire, SAM Research AG, Zurich (2011)

31. Porter, M.E., Kramer, M.R.: Creating Shared Value. Harvard Business Review 1(2), 2-17 (2011)

32. Hockerts, K.: The SusTainAbility Radar. Greener Management International 99(25), 29-49 (1999)

33. Grauler, M., Freundlieb, M., Ortwerth, K., Teuteberg, F.: Understanding the beliefs, actions and outcomes of sustainability reporting: An experimental approach. Information Systems Frontiers 15(5), 779-797 (2013)

34. SO SMART, Socially Sustainable Manufacturing for the Factories of the Future Coordination and Support Action (2014), http: / / www . sosmarteu .eu /

35. WCED,Our common future: the Bruntland report, Oxford University Press, New York (1987)

36. Social Accountability International, Social Accountability 8000 International Standard, New York: Social Accountability International (2001)

37. UN Global Compact, United Nations Global Compact - Strategy (2014-2016)

38. Littig, B., Griessler, E.: Social sustainability: a catchword between political pragmatism and social theory. Internation Journal of Sustainable Development 8(1/2), 65-79 (2005)

39. Hodge, R., Hardi, P.: The need for guidelines: the rationale underlying the bellagio principles for assessment, in Assessing Sustainable Development. Principles in Practice, International Institute for Sustainable Development, Winnipeg, Manitoba, pp. 7-20 (1997) 